\title{
REFLEXÕES SOBRE O USO DE ÁGUAS RESIDUÁRIAS NA CIDADE DE SÃo PAULO
}

\author{
Silvana Audrá Cutolo* \\ Aristides Almeida Rocha*
}

\begin{abstract}
RESUMO: Os riscos epidemiológicos associados ao uso de águas residuárias no meio urbano, seja pela presença de agentes infecciosos e parasitários, seja pela toxicidade devido a contaminantes carcinogênicos e mutagênicos, bem como seus efeitos sobre o ambiente têm sido alvo de preocupação da comunidade técnica e científica. Contudo, o tratamento de água e dos esgotos sanitários não são suficientes para assegurar a eliminação de agentes patógenos e tóxicos. A adoção de "barreiras múltiplas" para a eliminação de substâncias tóxicas e contaminantes biológicos, garantindo a qualidade das águas, é recomendada pela Organização Mundial de Saúde.
\end{abstract}

PALAVRAS-CHAVE: agentes infecciosos e parasitários, compostos mutagênicos e carcinogênicos, uso de águas residuárias, barreiras múltiplas e saúde pública

\footnotetext{
* Doutora em Saúde Pública, Bióloga do Departamento de Saúde Ambiental da Faculdade de Saúde Pública da Universidade de São Paulo e-mail: cutolosa@usp.br;

** Professor Titular do Departamento de Saúde Ambiental da Faculdade de Saúde Pública da Universidade de São Paulo Av. Dr. Arnaldo 715 - 01246-904 Cerqueira César - São Paulo/SP Fone: 30667712 /Fax: 30667732 e-mail: arirocha@usp.br
} 


\section{AS ENFERMIDADES DE VEICULAÇÃO HÍDRICA NO MEIO URBANO e A VISÃO AMBIENTAL}

A importância das condições do clima e tempo, das propriedades e características das águas e de outras influências ambientais na ocorrência de doenças foram destacadas nos estudos hipocráticos (BUCK et al, 1988; apud CZERESNIA, 1997). Trabalhos de Baillou, no período de 1538 - 1616, influenciados pelos estudos de Hipócrates, dissertando sobre a distribuição sazonal de doenças, ressaltam as relações com os diferentes estados e condições atmosféricas (ROSEN, 1994; CZERESNIA, 1997).

Em certo período da Idade Média houve uma estagnação e retrocesso em relação aos aspectos sanitários, sendo os detritos acumulados nas cidades, criando problemas de saúde pública. Especialmente no final do século XVIII e na primeira metade do século XIX, o processo de urbanização e industrialização na Europa provocou transformações sociais, levando à deterioração das condições de vida e de trabalho, aumentando a ocorrência de epidemias. O movimento social desse período demonstrou a importância da relação entre doença e meio ambiente, sendo identificados vários fatores de influência (a fome, a miséria, a exploração e a opressão social) como determinantes no desencadeamento das doenças (ROSEN, 1994).

Historicamente registra-se que, na metade do século XVIII, na França, as práticas de saúde pública eram centradas no controle ambiental, preocupando-se com o acúmulo e circulação das água e do ar e, em certos locais, com a disposição de esgotos e em relação à situação dos mananciais nas cidades (FOUCAULT, 1990; FABRE, 1993).

Ressalta-se que o conceito de infecção, desde a antiguidade clássica, levou às primeiras reformas de saúde pública, nas quais as epidemias eram enfocadas como resultantes das condições ambientais, destacando-se, além dos fatores já citados, as habitações sem ventilação e superlotadas (HOCHMAN, 1998).

Desse contexto, surgiu a teoria miasmática, entendendo-se que as doenças seriam transmitidas por miasmas, surgidos da decomposição da matéria orgânica animal e vegetal, resultante daquelas condições ambientais antes especificadas (HOCHMAN, 1998).

As grandes epidemias como a de febre amarela, a de cólera e a de gripe espanhola têm sido os exemplos mais citados como decorrentes dos impactos sociais, culturais e políticos dos séculos XIX e XX. Também necessário é enfatizar que as principais ações de 
combate às epidemias ocorreram, então, com base na análise e ações sobre as condições sociais e ambientais. Esse programa ambiental fundamentou as primeiras reformas sanitárias na Europa e nos Estados Unidos (HOCHMAN, 1998).

Assim pois as políticas públicas de saúde tiveram efetividade maior na atenção e promoção de programas destinados à remoção dos agentes difusores de doenças epidêmicas como remoção, destinação adequada e tratamento de resíduos sólidos; tratamento de esgotos sanitários e de águas poluídas; e melhorias das habitações inadequadas e com superpopulação (ROSEN, 1994). Com a implantação desses programas, que deram importância aos fatores geradores das péssimas condições de vida vigentes nas cidades, foram criados os primeiros serviços públicos urbanos, que trouxeram um grande e positivo impacto na coletivização do bem-estar (DE SWAAN, 1990 apud HOCHMAN, 1998).

A poluição dos rios é fenômeno conhecido desde a antiga Macedônia, quando Aristóteles estudou com interesse alguns organismos que se desenvolviam nas águas poluídas (BRANCO, 1983). O problema intensificou-se com a introdução dos sistemas de esgotos nas cidades, técnica que, no Império Romano já era largamente utilizada com os canais de esgoto destinados ao afastamento dos dejetos.

Entretanto, esses conhecimentos parecem ter sido esquecidos, pois em 1848 o marinheiro John Harnold, recém chegado de Hamburgo onde a cólera grassava, trazia para Londres essa enfermidade descrita por SNOW (1967). Esse primeiro caso descrito reavivou os antigos ensinamentos, provando-se pela primeira vez, a vinculação da ingestão de água contaminada e a transmissão, por meio de estudo e raciocínio epidemiológico que se tornou clássico na literatura médica (CZERESNIA, 1997).

Assim em que pese a existência de sistemas eficientes de tratamento de água implantados entre os séculos XVI a XVIII, a relação causal entre qualidade de água e doença, cientificamente somente foi estabelecida a partir dos trabalhos de SNOW (CZERESNIA, 1997).

Dando um salto na história, verifica-se que, atualmente, o abastecimento de água deficiente e pouco seguro representa, nos países sub-desenvolvidos e em desenvolvimento, um problema permanente à saúde pública. Mais de três milhões de crianças menores de cinco anos morrem, todos os anos, por complicações diarréicas, causadas, principalmente, por águas contaminadas (OPS, 1996). 
O ser humano, um ser gregário, vivendo em sociedade, concentrado sobretudo no meio urbano, assumiu que os ecossistemas naturais possuem certa capacidade de assimilação dos despejos industriais e domésticos por ele produzidos. Assim ocorre com o meio hídrico onde a presença de agentes infecciosos e parasitários representa um sério risco à saúde humana (ZIOLLI \& JARDIM, 1998).

Como enfatiza MANCUSO (1988), o lançamento de esgotos "in natura" em corpos d'água foi, e continua sendo, uma alternativa muito utilizada em várias cidades. Com o adensamento populacional nos grandes centros urbanos e o incremento no lançamento de despejos domésticos e industriais, nota-se que os sistemas aquáticos não mais estão suportando as cargas tão elevadas de matéria orgânica e inorgânica de poluentes, o que impede ou dificulta a realização do processo de autodepuração natural, que possibilitaria a eliminação e remoção de impurezas, por meio da assimilação, decantação, digestão e oxidação de vários compostos (BRANCO, 1983).

A prática de despejar águas residuárias, independentemente de serem ou não tratadas, em sistemas hídricos superficiais (rios, lagos, represas, etc.) é uma solução normalmente adotada por várias comunidades em todo mundo. Contudo, esses sistemas aquáticos servem de fonte de abastecimento, muitas vezes, a mais de uma comunidade. Há casos em que a mesma cidade que lança seus esgotos nos corpos d'água, utiliza-se deste mesmo sistema como fonte de abastecimento; são exemplos várias cidades no vale do Rio Paraíba no Estado de São Paulo, que captam água e dispõem seus esgotos no mesmo rio (MANCUSO, 1988).

O avanço tecnológico induziu o desenvolvimento e instalação de estações de tratamento de esgotos para conter e minimizar a poluição dos sistemas aquáticos. Estas têm a finalidade de reduzir as concentrações de matéria orgânica presente nos esgotos, mas constituem processos tecnológicos não suficientes para a eliminação de substâncias tóxicas e mesmo de patógenos (ROCHA, 1992; HESPANHOL, 1997).

\section{A REGIÃo METROPOLITANA dE SÃo PAULO E O REUSO dE ÁGUA}

O saneamento no Brasil, da década de 1910 até a Primeira República, foi marcado pelo crescimento de uma consciência entre as elites em relação aos grandes problemas sanitários do país e de que o Estado nacional deveria assumir mais a responsabilidade pela saúde da população e salubridade do território (HOCHMAN, 1998). 
A partir da reformulação e ampliação dos serviços sanitários, os Estados passaram a obter auxílio federal, para implantação de ações de saúde e saneamento. São Paulo foi o único estado a se dedicar a uma ampla política sanitária, desde o início da República, e que se manteve autônomo em relação aos serviços federais. A cidade de São Paulo despontava como centro do poder político-econômico, e a insalubridade ambiental ameaçava e afetava seriamente as bases da economia paulista e suas relações com o comércio exterior (HOCHMAN, 1998).

O estado atual de degradação dos recursos hídricos da cidade de São Paulo, pertencentes a Bacia do Alto Tietê onde está localizada toda a região metropolitana, deve ser compreendido reportando-se primeiramente à evolução do desenvolvimento e ocupação territorial do Estado paulista.

A conquista da hegemonia econômica do Estado de São Paulo ocorreu em meados do século XIX, quando tornou-se o maior beneficiário do ciclo do café. A produção cafeeira ultrapassou a região de Campinas com destino ao oeste paulista, contribuindo para a construção de estradas de ferro, sendo que a primeira interligava a cidade de São Paulo ao porto de Santos (SCHIFFER, 1999).

Territorialmente, o estágio de industrialização brasileira significou a concentração de capital e atividades produtivas no maior parque industrial do país, sendo que $2 / 3$ das aplicações estrangeiras foram alocadas em São Paulo. A predominância absoluta dos novos investimentos industriais no Estado de São Paulo concentrou-se na região metropolitana com $47,4 \%$ dos estabelecimentos industriais (SCHIFFER, 1999).

A crescente urbanização que acompanhou o processo de industrialização fez com que fossem desaparecendo as zonas rurais que separavam a Capital de sua circunvizinhança, dando lugar a uma faixa contínua de indústrias e habitações, extravasando os limites municipais. A consolidação da metropolização ocorreu na década de 1950 com a implantação de diversas indústrias de bens de consumo, intermediários e de capital (EMPLASA, 2001).

Todo o incremento industrial e o crescimento demográfico provocariam novas demandas deágua. O abastecimento de água da cidade de São Paulo, que no fim do século XVIII era proveniente dos rios Anhangabaú e Tamanduateí, teve de ser ampliado, iniciando-se um processo mais sistemático de captação e adução. A população da Capital era abastecida com cerca de 336.000 litros, e os restantes ( \pm 100.000 litros) eram retirados de cisternas abertas do rio Tamanduateí e do Córrego Lavapés (EMPLASA, 2001). 
A Companhia Cantareira, criada em 1882, implantou um plano de abastecimento para a captação de água do Ribeirão Pedra Branca na Serra da Cantareira. Na sequência, por volta de 1906, iniciou-se a captação da adutora do Cabuçu para 40 milhões de litros. Um novo reservatório foi construído na Consolação para 19 milhões de litros, sendo demolida a caixa d' água da rua Quintino Bocaiúva, no centro da cidade, pois a água não era potável (EMPLASA, 2001).

A rápida urbanização da cidade de São Paulo alterou de forma irreversível o ambiente natural, tornando-se um ambiente artificial. Dados da literatura indicam que uma cidade com um milhão de habitantes ocupando cerca de $250 \mathrm{~km}^{2}$ precisa de $8000 \mathrm{~km}^{2}$ para o fornecimento de alimentos e de sete bilhões e meio de litros de água por dia (ODUM, 1986).

Com enfatiza ODUM (1986) o meio urbano de uma a cidade industrializada, como por exemplo o município de São Paulo, pode ser considerado como um ecossistema heterotrófico, dependente de grandes áreas externas para a obtenção de energia, alimentos, água e outros materiais.

Atualmente, o município de São Paulo alberga cerca de 10.000 .000 milhões de habitantes, em uma área total de $1525 \mathrm{Km}^{2}$, e densidade demográfica de $6823,68 \mathrm{hab} / \mathrm{Km}^{2}$ (IBGE, 2000).

O consumo de água é dependente de vários fatores, tais como os hábitos, poder aquisitivo, nível de educação em saúde da população, características climáticas, e seleção adequada dos sistemas de abastecimento e esgotamento sanitário. Para o tamanho da cidade de São Paulo são recomendados volumes diários de 350 litros de água tratada por habitante (MOTA, 1999).

Contudo, o Município de São Paulo localizado na Bacia Hidrográfica do Alto Tietê, formada pelos rios Tietê, Tamaduateí e Pinheiros recebe diariamente 1100 toneladas de esgotos, sendo 800 toneladas de origem doméstica e 300 toneladas de origem industrial. Esses rios são ainda depositários de descargas de galerias pluviais, águas de escoamento superficial, de infiltração e da disposição direta de detritos (ROCHA, 1994).

A carência e a demora na implantação de medidas de saneamento levam, consequentemente, como visto, à propagação de diversas enfermidades. MOTA (1999), salienta que alguns dados sobre a saúde dos brasileiros são indicadores das precárias condições de saneamento ainda existentes; ocorrem $30 \%$ dos óbitos de crianças menores 
de 1 ano devido às diarréias, tendo-se $60 \%$ dos casos de internações em pediatria decorrentes da falta de saneamento. Existem ainda 5,5 milhões de casos de esquistossomose no país.

Na cidade de São Paulo, AKERMAN (1996) assinala que 43,5\% da população vive em áreas com as piores condições socioeconômicas e de ambiente, enquanto $9,2 \%$ dos habitantes residem nas áreas com as melhores condições. As doenças respiratórias são a principal causa de morte em crianças de 0 a 4 anos, seguida por doenças infecciosas e parasitárias. Do total da população da cidade de São Paulo, $59 \%$ dos habitantes vivem em habitações precárias e $16 \%$ sem nenhum acesso a redes de esgoto (JACOBI, 1990).

No Município de São Paulo, em área de complexa estrutura urbana, social, econômica e ambiental, agravada pelo caos demográfico, o desenvolvimento desordenado da ocupação do solo no entorno das áreas de proteção de mananciais induz às precárias condições de saúde de parcela da população (ROCHA, 1994).

Quanto ao abastecimento de água na cidade de São Paulo houve uma crise que teve início devido à expansão da malha urbana, com a implantação de loteamentos industriais e populares no bairro de Santo Amaro, em áreas de proteção de manaciais junto às represas da Guarapiranga e Billings. Assim, a água está cada vez mais escassa, principalmente na Região Metropolitana de São Paulo, que se viu obrigada a importar água de outras bacias hidrográficas (MELCHOR E COLS, 1974; ANONYMUS, 1992).

Grande parte do Município de São Paulo situa-se nos $5.650 \mathrm{Km}^{2}$ da Bacia Hidrográfica do Alto Tietê, uma cornubação de 39 municípios, que apresentava 18,4 milhões de habitantes em 1990. Atualmente, só a cidade de São Paulo conta com 10 milhões de habitantes (IBGE, 2000).

Os principais reservatórios responsáveis pelo abastecimento de água da Região Metropolitana de São Paulo são Cotia, Alto Tietê, Rio Claro, Rio Grande, Guarapiranga e Cantareira, estando alguns seriamente comprometidos do ponto de vista sanitário acarretando uma diminuição da capacidade produtora (COMITÊ DE BACIA DO ALTO TIETÊ, 2001).

Entretanto, houve um aumento significativo da capacidade de suprimento da represa do Guarapiranga, não só pela adução do Capivari- Monos como também em função da interligação desse sistema com o rio Taquacetuba proveniente da represa Billings (Gráfico 1). 
Gráfico 1 - Capacidade produtora $\left(\mathrm{m}^{3} / \mathrm{s}\right)$ dos reservatórios do Município de São Paulo nos anos de 1999, 2000 e 2001 (COMITÊ DE BACIA ALTO TIETÊ, 2001).

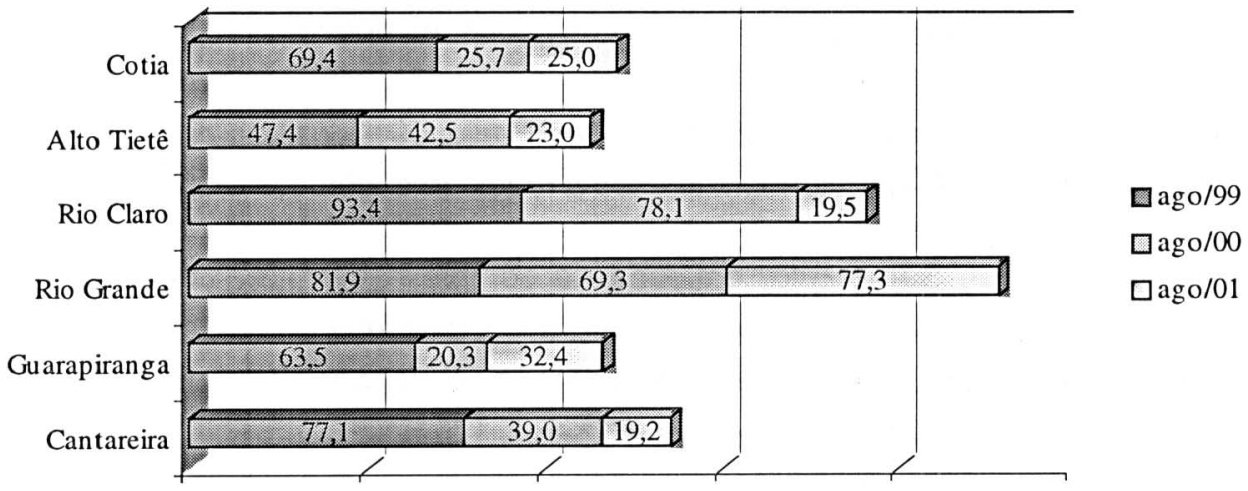

A Bacia da Cantareira, o principal sistema de abastecimento do Município de São Paulo, apresenta uma queda na capacidade comparando-se os anos de 1999, 2000 e 2001, mesmo sendo esse período considerado de estiagem, e de poucas chuvas.

Como enfatiza TEIXEIRA (1996), no ambiente não há separação absoluta entre ar, águas e solos, formando todos um conjunto inseparável, no qual qualquer alteração de um repercute no outro. Portanto, a queda da capacidade dos sistemas de abastecimento está intrinsicamente ligada às alterações climáticas, observadas nos últimos tempos, e ao aumento do período de seca, não só nessa região, como praticamente em toda a superfície terrestre. Daí a necessidade de trazer água de áreas tão distantes da capital, e com gastos elevados de infra-estrutura e operacionais.

O fenômeno da escassez de água no Município São Paulo, deve-se, também, ao mau gerenciamento dos recursos hídricos, uma vez que os Rios Tietê, Pinheiros e Tamanduateí são bastante volumosos, mas altamente impactados com o recebimento de esgotos domésticos e industrias, a inadequada disposição de resíduos sólidos, e ausência de políticas públicas para um planejamento urbano adequado, respeitando essas áreas de 
proteção e ao mesmo tempo de risco. A entrada de despejos de diversas fontes pode transformar esses mananciais em fontes de transmissão de diversos patógenos como é o caso dos parasitas intestinais e o vibrião do cólera, que acometeu o Perú e outros países da América do Sul (WEF, 1996).

Essa situação do abastecimento de água na cidade de São Paulo está associada aos riscos à saúde pública, tornando-se crítica, no período de estiagem quando há diversos racionamentos em vários bairros em face da escassez de água. Nesses períodos há sensível queda na quantidade e qualidade, prejudicando cerca de 1/3 da população abastecida, correspondendo a 3,5 milhões de habitantes, principalmente aquela servida pelo sistema do Guarapiranga (ANONYMUS, 1992).

Um outro ponto é que a poluição ultrapassa as fronteiras entre bairros, cidades, estados e países (ODUM, 1986). Esse fato é observado ao longo do Rio Tietê, que tem seu curso passando por várias cidades, que antes não apresentavam problemas de poluição das águas e, hoje, se apresentam totalmente poluídas como, por exemplo, a cidade de Pirapora do Bom Jesus, próxima à cidade de São Paulo (MANCUSO, 1988).

avanço tecnológico propiciou o desenvolvimento e instalação de estações de tratamento de esgotos para conter e minimizar a poluição dos sistemas aquáticos, com a finalidade de reduzir as concentrações de matéria orgânica presente nos esgotos domésticos. No entanto, como salientado, verifica-se que estas tecnologias são ineficientes para a eliminação de patógenos e substâncias tóxicas das águas residuárias (HESPANHOL, 1997).

O reuso de águas residuárias em nível urbano torna-se uma importante estratégia para o município, principalmente nesses períodos críticos. As principais vantagens do reuso urbano, com o estabelecimento de critérios para o uso adequado em todas atividades produtivas, são a preservação da disponibilidade e da qualidade dos recursos hídricos (PAZ e col, 2000).

No meio urbano, os benefícios econômicos no uso de águas residuárias devem ser considerados como sendo necessários na lavagem de pavimentação, irrigação de parques e campos desportivos, industrial e outros (HESPANHOL, 1997).

Os riscos epidemiológicos, no uso de águas residuárias no meio urbano devem ser considerados, uma vez que essas águas são líquidos procedentes da atividade humana, que geralmente são lançadas em cursos ou massas d'água continentais. Tem-se a eliminação 
de patógenos de pessoas doentes ou portadoras em cursos d'água, assim como o lançamento de metais pesados, substâncias tóxicas e carcinogênicas, entre outras (SEOANEZ CALVO, 1995). A presença de Salmonella sp, Shigella sp, Yersinia sp, Vibrio cholerae, Cryptosporidium sp, Entamoeba histolytica, Giardia lamblia, Balantidium coli, Toxoplasma gondii, Ascaris lumbricoides, Trichuris trichiura, Toxocara canis, Taenia saginata, Taenia solium, Necator americanus, Hymenolepis nana representam risco epidemiológico à saúde pública (EPA, 1992).

\section{BARREIRAS MÚLTIPLAS - PRINCIPAIS TÉCNICAS DE RECUPERAÇÃO DAS ÁGUAS CONTAMINADAS PARA REUSO}

Uma estratégia para minimizar os problemas de escassez de água é o reuso, devendo ser considerados devidamente os possíveis problemas da presença de agentes patogênicos.

Segundo RICE \& ROBSON (1982), a filosofia e prática Européia de tratamento de água difere significativamente da norte americana. Enquanto os Europeus tradicionalmente partem da verificação da qualidade da água e, em função da qualidade a ser alcançada, projetam o sistema de tratamento mais adequado através da inclusão de operações e processos unitários adequados àquela particular situação, até recentemente, nos Estados Unidos, a ênfase era dada ao chamado sistema convencional de tratamento com visão corretiva.

Assim, a manutenção da qualidade bacteriológica da água que era o grande objetivo a ser alcançado, nos Estados Unidos, era obtida através da adição de produtos químicos, havendo pouca preocupação com sua qualidade química (RICE \& ROBSON, 1982).

A prática Européia difere bastante dessa tradicional postura norte americana com relação às altas dosagens de produtos químicos, particularmente o cloro, e a não utilização de processos biológicos inseridos em sistemas de potabilização (RICE \& ROBSON, 1982).

A qualidade da água de abastecimento deve ser preservada da contaminação por esgotos, adotando-se uma série de tratamentos de águas residuárias antes de serem lançadas nos corpos receptores denominada de barreiras múltiplas, que proporcionem a máxima proteção contra os patógenos de transmissão hídrica (OPS, 1996). 
A falta de atenção as barreiras múltiplas foi a principal causa da rápida transmissão de cólera em toda América Latina, depois de sua introdução no Perú em 1991. Em 1993, nos Estados Unidos, ocorreu uma epidemia de origem hídrica, devido a contaminação das águas de abastecimento, provocada pelo protozoário Cryptosporidium parvum, causando gastrenterites em mais de 400.000 pessoas em Milwaukee (Wisconsin). Assim, as epidemias de origem hídrica propagam-se sempre que as fontes de abastecimento de água são contaminadas e os sistemas de tratamento tem baixo desempenho operacional (OPS, 1996).

Devido as diversas variáveis associadas a contaminação das águas é conveniente aplicar uma série de tratamento aos esgotos antes de serem lançados nos corpos d'água receptores, auxiliando os processos naturais de autodepuração das águas e os sistemas de tratamento das águas para abastecimento público. As barreiras múltiplas são formadas por um conjunto de tratamentos, incluindo: coleta e tratamento de todas as águas residuárias; limitação do lançamento de águas residuárias tratadas para impedir a sobrecarga nos ecossistemas aquáticos naturais; manejo integrado das bacias coletoras e uso do solo com o objetivo de proteger da contaminação os cursos d'água superficiais e subterrâneos; tratamento apropriado da águas de abastecimento com desinfecção e filtração para assegurar a proteção dos consumidores; e proteção do sistema de distribuição de água potável (OPS, 1996).

No quadro a seguir pode-se observar o conjunto de tratamentos, formando as barreiras múltiplas para controle dos coliformes fecais nas águas contaminadas, que são bactéria indicadoras de contaminação fecal.

A aplicação das barreiras múltiplas no Brasil torna-se um instrumento de proteção à saúde pública, pois nos métodos convencionais de tratamento de esgotos acentua-se a redução ou remoção de matéria orgânica e de sólidos em suspensão. Porém, no uso das águas residuárias faz-se necessário a eliminação de agentes patógenos (OMS, 1989). 
Quadro 1 - Barreiras microbianas: controle de

coliformes fecais em água contaminada.

\begin{tabular}{lll}
\hline Fontes & \multicolumn{2}{c}{ Coliformes Fecais (CF) } \\
\hline Coliformes fecais em excretas humanos & $1950000000 /$ pessoa/dia \\
Águas residuárias municipais sem tratamento & $8260000 / 100 \mathrm{ml}$ \\
Reduções por tratamentos de esgotos & Redução Acumulativa (\%) & CF Sobreviventes \\
Tratamento Primário & 50 & 4130000 \\
Tratamento Secundário & 80 & 1652000 \\
Tratamento Terciário & 98 & 165200 \\
Desinfecção & 99,99 & 800 \\
& $10-50$ & $400-700$ \\
Autodepuração e diluição do efluente & & \\
Tratamento de água para abastecimento & Redução Acumulativa (\%) & CF Sobreviventes \\
Armazenamento da água sem tratamento & 50 & $200-350$ \\
Coagulação/ sedimentação & 60 & $80-140$ \\
Filtração & 99,9 & $0,8-1,4$ \\
Desinfecção & 99,9999 &, $00008-, 00014$ \\
\hline
\end{tabular}

Fonte: GELDREICH (1986)

Para a validação do emprego das barreiras múltiplas, além do controle de coliformes fecais em água contaminada, podem ser adotados indicadores de patogenicidade como por exemplo bactérias Escherichia coli, Salmonella sp, Vibrio cholerae; protozoários intestinais Cryptosporidium parvum, Entamoeba hystolitica e Giardia lamblia; helmintos intestinais Ascaris lumbricoides, Enterobius vermiculares, Trichuris trichiura (TCHOBANOGLOUS, 1991; AYRES \& MARA, 1997). Através do monitoramento desses agentes infecciosos e parasitários pode-se, com uso de estudos epidemiológicos, estimar o estado de saúde da população e elaborar padrão de qualidade, afim de tornar as águas residuárias aptas ao consumo em qualquer atividades (CROSS, 1985; ROCHA, 1995). 


\section{CONCLUSÕES}

A preocupação com os agentes infecciosos e parasitários, contaminantes químicos, em particular com os agentes carcinogênicos e mutagênicos, vem ganhando corpo junto à comunidade técnica e científica, havendo propostas de decretos e legislação para o controle mais restritivo da qualidade das águas de consumo humano. Entretanto, pouco se faz em relação à prevenção e controle das águas residuárias, impedindo o uso seguro dessas águas como alternativa no meio urbano, por representar um risco potencial à saúde da população. Dentre as medidas preventivas está a elaboração de instrumentos legislativos mais restritivos com portarias e decretos em relação ao tratamento e ao lançamento de águas residuárias, assim como ocorre com as águas destinadas ao abastecimento potável com a nova Portaria MS 1469 (2000). Dentre as medidas corretivas estão a adoção de métodos adequados a cada situação, levando em consideração circunstâncias físicas, sociais, políticas e econômicas de cada localidade, na minimização de cargas poluidoras; e a vigilância sanitária adotando indicadores de patogenicidade como agentes bacterianos e parasitológicos.

Com relação às técnicas de tratamento de águas que recebem altas cargas poluidoras, a tendência atual para o reuso é a adoção do princípio das múltiplas barreiras segundo o qual a responsabilidade pela remoção de um dado contaminante não deve ser atribuída a apenas um conjunto de sistemas de tratamento de águas residuárias, mas também minimizar a contaminação das fontes de abastecimento. Para adoção das múltiplas barreiras seria importante a avaliação da bacia hidrográfica, observando os pontos críticos para o reuso das águas residuárias tratadas.

Face à explosão populacional na cidade de São Paulo e a intensificação do processo produtivo, o uso das águas residuárias tem sido apontado como inevitável, havendo, portanto, a necessidade do desenvolvimento de novas tecnologias de tratamento de água e controle de qualidade adequados e confiáveis.

\section{REFERÊNCIAS BIBLIOGRÁFICAS}

AKERMAN, M.; CAMPANARIO, P.; MAIA, P.B. Saúde e meio ambiente: análise de diferenciais intra-urbanos, Município de São Paulo, Brasil. Revista de Saúde Pública, São Paulo, v. 30, n. 4, p. 372-82, 1996. 
GUARAPIRANGA: é preciso salvar este manancial de 10 metros cúbicos por segundo. Revista DAE, São Paulo, v. 52, n. 164, p.1-35, 1992.

AYRES, R.M.\& MARA, D.D. Análises de águas residuales para su uso en agricultura. Ginebra. Organización Mundial de la Salud, 1997.

BAKER, M.N. The quest of pure water. 2a. ed. Washington, American Water Works Association, v. 1, 1981

BRANCO, S.M. Poluição: a morte de nossos rios. São Paulo: ASCETESB, 1983.

COMITÊ DE BACIA DO ALTO TIETÊ. Capacidade produtora dos reservatórios do Município de São Paulo. Informativo do Comitê da Bacia Hidrográfica do Alto Tietê, São Paulo, v. 5, n. 29, p. , 2001.

CROSS, P. Part I: Existing practices and beliefs in the utilization of human excreta. In: International reference centre for waste disposal. Health aspects of nightsoil and sludge use in agriculture and aquaculture. 1995, (Report n. 04), p. 1- 20.

CZERESNIA, D. Do contágio à transmissão: ciência e cultura na gênese do conhecimento epidemiológico. Rio de Janeiro: FIOCRUZ, 1997.

EMPLASA. Memória urbana: a Grande São Paulo até 1940. São Paulo: Arquivo do Estado, Imprensa Oficial, 2001. 3 v.

ENVIRONMENTAL PROTECTION AGENCY Environmental regulations and technology: control of pathogens and vector attraction in sewage sludge (including domestic septage) under 40 CRF Part 503. U.S. Cincinnati, 1992. (OH. EPA/625-R-92/013).

FABRE, G. La notion de contagion au du sida, ou comment interfèrent logiques sociales et catégories médicales. Sciences Sociales et Santé, Paris, v. 11, n. 1, p. 5-32, mar, 1993.

FOUCAULT, M. Microfísica do poder. Rio de Janeiro: Graal, 1990.

FORATTINI, O. P. Ecologia, epidemiologia e sociedade. São Paulo: Artes Médicas: EDUSP, 1992. 
FUNDAÇÃO IBGE. Sinopse preliminar do censo demográfico. Rio de Janeiro: IBGE, 2000, v. 7.

GELDREICH, E.E. Control of microorganisms of public health concern in water. Journal Environmental Science Health, New York, v. 29, p. 34-7, 1986.

HESPANHOL, I. Wastewater as a resource. In: WORLD HEALTHORGANIZATION Water pollution control: a guide to the use of water quality manegment principles. Geneva: UNEP, 1997.

HOCHMAN, G. A era do saneamento: as bases da política de Saúde Pública no Brasil. São Paulo: Hucitec/ANPOCS, 1998.

JACOBI, P. Habitat and health in the municipality of São Paulo. Environment Urban, v. 2, p. 33-45, 1990.

MANCUSO, P.C.S. O Reuso de Água. São Paulo, 1988. [Dissertação de Mestrado em Saúde Pública da Faculdade de Saúde Pública da Universidade de São Paulo].

MELCHOR, A. et al. Preservação de mananciais para abastecimento - Guarapiranga, um modelo de preservação. Revista DAE, v. 35, p.14-25, 1974.

MOTA, S. Saneamento. In: ROUQUARIOL, M. Z. Epidemiologia e saúde. $5^{\mathrm{a}}$ ed. Rio de Janeiro: Editora FIOCRUZ, 2000.

ODUM, E. P. Ecologia. Rio de Janeiro: Guanabara, 1986.

ORGANIZACIÓN MUNDIAL DE LA SALUD. Directrices sanitarias sobre el uso de aguas residuales em agricultura y acuicultura. Ginebra, 1989. (Serie de Informes Técnicos 778).

ORGANIZACIÓN PANAMERICANA DE LA SALUD. La calidad del agua potable em América Latina: ponderación de los riesgos microbiológicos contra los riesgos de los subproductos de la desinfección química. Argentina, 1996.

PAZ, V. P. S; TEODORO, R. G. F. \& MENDONÇA, F. C. Recursos hídricos, agricultura irrigada e meio ambiente. Revista Brasileira de Engenharia Agrícola e Ambiental, Campina Grande, v. 4, n. 3, p. 465-72, 2000. 
RICE, R.G. \& ROBSON, C.M. Biological activated carbon: enhanced aerobic biological activity in GAC systems. Ann Arbor: Ann Arbor Science, 1982.

ROCHA, A.A. et al. Análise dos problemas de meio ambiente urbano da cidade de São Paulo. São Paulo: SBPC, 1992.

ROCHA, A.A. A problemática da água. In: LEITE, J.L. Problemas chave do meio ambiente. Ed. EXPOGEO. Salvador: Instituto de Geociências da UFBA, 1994. p. 91-113.

ROCHA, A.A. Ciências do ambiente, saneamento, saúde pública. São Paulo: Departamento de Saúde Ambiental/Faculdade de Saúde Pública da Universidade de São Paulo, 1995, p. 168-170.

ROSEN, G. Uma história da saúde pública. São Paulo: Hucitec/EDUSP, Abrasco, 1994.

SCHIFFER, S.R. São Paulo como pólo dominante do mercado unificado nacional. In: DEÁK, C; SCHIFFER, S. R. O processo de urbanização no Brasil. São Paulo: EDUSP, 1999

SEOANEZ, C. M. Aguas residuales: tratamientos naturales de bajo costo y aprovechamiento. Madrid: Mundi-Prensa, 1995.

SNOW, J. Sobre a maneira de transmissão do cólera. Rio de Janeiro: Agência Norte Americana para o Desenvolvimento Internacional - USAID, 1967.

TCHOBANOGLOUS, G., BURTON, F.L. Wastewater engineering, disposal and reuse. $3^{\mathrm{a}}$ ed. Metcalf \& Eddy, INC, 1991.

TEIXEIRA, P.F.P. Manual sobre vigilancia ambiental. Organización Panamericana de la Salud, 1996.

WATER ENVIRONMENT FEDERATION. Wastewater disinfection. Water Environment Federation (WEF). III. 1996. (Series: Manual of Practice, FD; 10).

WORLD HEALTH ORGANIZATION. Guide to short-term tests for detecting mutagenic and carcinogenic chemicals. Geneva, 1985. (Environmetal Health Criteria 51). 
ZIOLLI, R. L.; JARDIM, W.F. Ensaios de toxicidade na avaliação da qualidade de águas: 0 estado da arte no Brasil. Revista de Engenharia Sanitária e Ambiental, v. 3, n. 1-2, p.10-4, 1998.

\section{CONSIDERATIONS ON WASTEWATER USE IN SÃO PAULO}

SUMMARY: Epidemiologic risks associated with urban wastewater use due to infection and parasitic agents, carcinogenics and mutagenics contaminants and their environment effects have been the concern of the technical and scientific communities. However, the treatment of water supplies and wastewater is not sufficient to assure the elimination of patogenics agents. WHO recommends the use of multiple barriers for the elimination of toxic substances and biological agents to secure the safety and quality of water.

KEYWORDS: infection and parasitics agents; mutagenic and carcinogenic contaminants; wastewater use; multiple barriers; public health 